\title{
A invenção da teatralidade ${ }^{1}$
}

Jean-Pierre Sarrazac ${ }^{2}$

A arte só pode reconciliar-se com sua própria existência ao exteriorizar seu caráter de aparência, seu vazio interior.

Adorno, Teoria estética. ${ }^{3}$

No início de Da arte do teatro", o Diretor, que acaba de conduzir o Amador de Teatro ao espaço teatral para que perceba seu "mecanismo" ("construção geral, cena, maquinaria dos cenários, equipamentos de luz e todo o resto"), pede a seu convidado para se sentar por "um instante na plateia" e se interrogar a respeito de "o que é a Arte do Teatro" ... A lição merece ser compreendida: jamais se deveria abordar a mínima questão de estética teatral sem se colocar, mesmo que mentalmente, diante da cena. Antes de refletir sobre o teatro é importante constatar que esse palco estreito - mas destinado a servir de pedestal a um universo - quando em repouso parece um deserto. Em outros tempos a cortina vermelha permitia que se dissimulasse esse vazio ao olhar dos espectadores; ela estava ali para dar passagem às miragens construídas nos bastidores. Hoje, a cortina de ferro, puramente funcional, interpõe-se entre o público e os artistas no início da representação apenas para sublinhar melhor essa lacuna, esse vazio da cena moderna. Atrás da cortina de veludo, nossos antepassados puderam pressentir a abundância e a plenitude de um teatro baseado na ilusão. No presente, mal a cortina de ferro acaba de se elevar e já sabemos que esse cenário, essa cenografia, jamais poderão

\footnotetext{
1 Texto publicado originalmente em: Jean-Pierre Sarrazac. "L'invention de La théâtralité". In Critique du theatre. De I'utopie au désenchantement. Paris: Circé, 2000, p. 53-71. A Presente tradução foi feita pela Profa. Dra. Sílvia Fernandes 2 Jean-Pierre Sarrazac é dramaturgo, diretor e professor emérito de estudos teatrais na Université Paris 3Sorbonne Nouvelle.

3 Theodor W. Adorno, Théorie esthétique, Klincksieck, Collection d’Esthétique, 1989. [Theodor W. Adorno, Teoria estética, trad.

4 Edward Gordon Craig, L’Art du theatre, Éditions O. Lieuter, 1942. Nova edição, Circé, coll. "Penser le theatre", apresentação de Georges Banu e Monique Borie, seguida de entrevista com Peter Brook, 1999. [Edward Gordon Craig, $A$ arte do teatro, trad.
} 
preencher o vazio da cena nem nos preencher - a nós, o público - com o benefício de suas aparências. A própria cena, especialmente a mais preenchida, continua vazia; e é justamente esse vazio - o vazio de toda representação - que ela parece destinada a exibir diante dos espectadores.

Aliás, suspeito que Gordon Craig e seu Diretor expuseram seu Amador de Teatro ao irremediável vazio da cena apenas para apresentá-lo à concepção de que a Arte do Teatro não tem nada a ver com a plenitude e a explosão da vida mas, ao contrário, liga-se aos movimentos subreptícios, erráticos e desencarnados da morte - "Essa palavra morte, nota Craig, naturalmente vem à cabeça por aproximação com a palavra vida, que todos os realistas afirmam.

\section{Ilusão ou simulacro?}

Supondo-se que a arte teatral do século $X X$ continue baseada na imitação - o que pode dar margem a discussões - na concepção de Craig e de muitos outros, aí incluídos diversos "realistas", já não implica a submissão do espectador a uma ilusão, mas a observação crítica de um simulacro... Sou tentado a dizer que a ribalta e a cortina vermelha foram de fato abolidas a partir do momento em que o espectador foi convidado pelos atores ou qualquer outro condutor do jogo - diretor, encenador, autor, etc. - a não se interessar pelo evento do espetáculo, mas pelo advento, no centro da representação, do próprio teatro - daquilo que se chama teatralidade...

Mudança de regime do teatro, que se liberta do espetacular associando o espectador à produção do simulacro cênico e a seu caráter processual. Mudança implícita e difícil de circunscrever em vários criadores. Mudança perfeitamente identificável e explícita em Brecht, quando pretende que "o teatro confesse que é teatro", e já visível em Pirandello: o Diretor de Esta noite se improvisa não anuncia ao público, a cada noite, que procura "mostrar o funcionamento desse jogo em estado puro, essa simulação, esse simulacro geralmente conhecido como teatro".

$\mathrm{Na}$ virada do século $\mathrm{XX}$, a exemplo de outras artes da representação, o teatro toma consciência de seu vazio interior e projeta esse vazio para o exterior. Evidentemente, tal reversão não poderia ocorrer sem a reunião de alguns pressupostos essenciais, de Zola a Craig, passando por Antoine, Lugné-Poe e Stanislávski: o surgimento do encenador moderno, que tende a tornar-se autor da representação; a emancipação da cena em relação ao texto; a focalização progressiva dos artistas na essência de 
sua arte, naquilo que é especificamente teatral; a autonomia completa - para além do compromisso e da união proposta pela síntese wagneriana das artes ou Gesamtkustwerk - do teatro e do teatral em relação às outras artes e técnicas que participam da representação... A cada vez que se tenta definir a revolução que se completa nesse momento da história do teatro coloca-se a ênfase na sagração do encenador e no fim da tutela absoluta do dramático sobre o teatral; mas seria lastimável esquecer outro fator cuja importância só é mensurável diante do buraco negro da cena: a revelação da teatralidade pela escavação, prospecção, investigação do teatro.

Cita-se, com frequência, a famosa definição de Roland Barthes de que "a teatralidade é o teatro menos o texto". Mas não deveria ser esquecida sua luminosa apresentação do Bunraku, essa forma teatral em que "as fontes do teatro são expostas em seu vazio" e "o que se expulsa da cena é a histeria, quer dizer, o próprio teatro, e o que se coloca no lugar é a ação necessária à produção do espetáculo: o trabalho substitui a interioridade". Se a teatralidade é o teatro enquanto forma autônoma, então esse processo de formalização não poderia completar-se sem o, esgotamento do conteúdo pela forma", como se lê nas Mitologias (a respeito do catch, tomado como paradigma de um teatro da exterioridade).

A ideia de um teatro crítico que vai germinar, nos anos cinquenta, à sombra do TNP de Vilar, do Berliner Ensemble de Brecht e do Piccolo Teatro de Strehler, não se limita à crítica social por meio do teatro, como às vezes se pretende. No espírito de Roland Barthes e Bernard Dort, os dois principais promotores dessa ideia, a dimensão crítica e política da atividade teatral só tem sentido se estiver fundada na crítica em ato do próprio teatro e na liberação do potencial de teatralidade. Por isso os editores da revista Théâtre Populaire elegem como alvo um teatro psicológico e burguês cujos valores apregoados são "a interioridade," o "natural” e a proclamada continuidade entre a realidade e o teatro. Ao contrário, os artistas e escritores mencionados, enfaticamente, por Dort e Barthes - Brecht, é claro, mas também Pirandello ou Genet - não deixam de insistir sobre a ruptura, a disjunção entre o real e a cena. Para responder ao mundo, para dar corpo à crítica da sociedade, o teatro deve proclamar, antes de tudo, sua insularidade: o palco já não está ligado à realidade por meio da peneira e do sifão

5 Craig considera-se o primeiro a definir essa arte em sua autonomia, quer dizer, independente da literatura e liberada dessa situação indivisa que, em Wagner, ainda a colocava sob o controle da música, da poesia, da pantomima e até mesmo da arquitetura e da pintura. 
dos bastidores ${ }^{6}$; não é mais o lugar de um transbordamento anárquico do real, mas um espaço virgem, um espaço vazio, uma página em branco em que vão se inscrever os hieróglifos em movimento da representação teatral.

O discurso dos defensores desse teatro crítico - que constitui, ao mesmo tempo, uma crítica do teatro - não é estranho às posições de Gordon Craig, mas delas se distingue em um ponto essencial: para Barthes e Dort um teatro da teatralidade não é incompatível com um teatro realista - ao menos com certo tipo de realismo... Ao defenderem o realismo épico, os dois críticos "brechtianos" demarcam, integralmente, as fronteiras com o realismo socialista e, de forma global, com todo sistema artístico que se pretende reflexo ou reprodução direta do real. Em Théâtre Populaire, o elogio dos efeitos críticos e políticos de espetáculos como Mãe coragem ou $A$ vida de Galileu liga-se ao reconhecimento do poder e da clareza de sua escritura cênica, em suma, de sua teatralidade. O teatro realista deixa de ser considerado uma esponja do real, para ser visto sobretudo como uma espécie de lugar in vitro: um espaço vazio onde se fazem experiências sobre o real, usando a teatralidade como único protocolo.

Nos anos sessenta, quando Barthes se distancia do teatro (e transfere sua teoria da teatralidade para outro lugar - para a questão do Texto) Dort segue sozinho ampliando a reflexão sobre o teatro e a teatralidade. Ele se interessa especialmente pelo processo de reteatralização do teatro, que culmina em Meyerhold na União Soviética dos anos vinte e trinta. Levar Meyerhold em consideração é constatar, forçosamente, com Josette Féral', que "a afirmação do 'teatral' como distinto do real é condição sine qua non da teatralidade em cena", e que "a cena deve falar sua própria linguagem e impor suas próprias leis." Mas a contribuição mais decisiva de Dort para as relações entre realismo e teatralidade é de iniciar uma verdadeira reavaliação de Stanislávski, de Antoine e do tão mal falado "naturalismo".

Ao apresentar Antoine como o "patrono"8 do teatro moderno, Dort se distancia do idealismo de Gordon Craig. Não vê menos teatralidade ou uma teatralidade menos

\footnotetext{
6 Ver o capítulo "Brecht em processo" do livro de Sarrazac Critique du theatre. De l'utopie au désenchantement. (N.T.) 7 Josette Féral, "La Théâtralité", Poétique n. 75, Éditions du Seuil, setembro 1988. O conceito de teatralidade, em seus múltiplos usos no teatro e fora do teatro, torna-se cada vez mais fluido e tende a se banalizar. Portanto, para uma melhor definição do conceito, eu proporia a comparação com o que chamo de teatralismo. "Teatralismo" designaria o contrário da teatralidade como é tratada aqui... O surgimento da teatralidade procede da pura emergência do ato teatral no vazio da representação. O reino do teatralismo remete a essa doença estética endêmica que faz com que o teatro sofra de sua própria ênfase e, de certo modo, de um excesso de si mesmo. Assim, quando Stanislávski declara que "O que faz désespérer do teatro é o teatro", não visa a teatralidade à Meyherhold, mas esse "teatralismo" enquanto estado histriônico e narcísico, manifestação redundante do teatro no teatro.
}

8 Bernard Dort, "Antoine le patron", Théâtre Public, op. cit. 
sutil nas encenações naturalistas de Antoine que nos espetáculos "simbolistas" e estilizados de um Lugné-Poe. Sem dúvida, o autor de Théâtre réel acredita que a verdadeira modernidade está mais presente no gesto experimental de colocar um fragmento de vida, um ambiente, sob a lente de aumento da quarta parede do que nas cerimônias fantasmáticas do Théâtre d'Art ou do Théâtre de l'Oeuvre, longinquamente inspiradas em Baudelaire e Wagner. Talvez ele consiga até mesmo discernir, sob a aparência de continuidade e unidade da representação naturalista, esse pontilhismo ou, sobretudo, esse divisionismo que Antoine e Stanislávski praticam. Com base nesse pressuposto, pode-se reavaliar o naturalismo teatral, considerando-o uma arte decididamente moderna e uma arte da teatralidade, ou seja, fundada na descontinuidade e nos vazios. Lugné-Poe, Craig, Copeau já não são os pais obrigatórios do teatro contemporâneo; outra genealogia está prestes a se desenhar. Segundo a fórmula de Dort, se Barthes sonhou com um teatro em que "a matéria se tornaria signo", a origem desse sonho não estaria exclusivamente em um teatro oriental hipercodificado como o Bunraku, mas também no realismo experimental de Brecht e seus predecessores Antoine e Stanislávski.

\section{O estar-aí do teatro}

Do vazio da cena - e no fundo pouco importa que seja ostensivo (palco nu) ou discreto (dispositivo realista ou mesmo naturalista) - surge o corpo do ator e qualquer outra partícula de teatro - figurino, elemento de cenário, iluminação, música etc. A partir do momento em que o palco não pretende mais ser contíguo e comunicante com o real, o teatro não é mais colonizado pela vida. O jogo estético desloca-se: não se trata mais de colocar em cena o real, mas de colocar em presença, confrontar os elementos autônomos - ou signos, ou hieróglifos - que constituem a realidade específica do teatro. Elementos discretos, separados, insolúveis, que remetem apenas ao enigma de sua aparição e seu agenciamento. Há uma oscilação do primado do real, que ainda era lei no século XIX, para o "Estar-aí" do teatro. Para essa literalidade que vai tornar-se, tanto para Brecht quanto para o Novo Teatro, a grande demanda dos anos cinquenta e sessenta. Artaud já a anunciava em 1926, sob a influência determinante do último Strindberg: "Não queremos criar, como se fez até aqui e como sempre se fez no caso do teatro, a ilusão daquilo que não é; ao contrário, pretendemos fazer

9 Josette Féral, "O naturalismo é, ele próprio, reconhecido como uma forma de teatralidade". 
surgir diante dos olhos um certo número de quadros, imagens indescritíveis, inegáveis, que falarão diretamente ao espírito. Os objetos, os acessórios, até mesmo os cenários no palco devem ser entendidos em sentido imediato, sem transposição: devem ser tomados não pelo que representam, mas pelo que realmente são na realidade"10?

O intermediário entre Artaud e os críticos "brechtianos" será Adamov, em um período em que ainda é classificado, com lonesco e Beckett, como puro vanguardista strindbergo-kafkiano... Quanto à definição desse Estar-aí do teatro - que deverá adquirir, na sequência, uma dimensão mais filosófica, mais heiddegeriana - ela está contida por inteiro em algumas linhas de um texto de 1950, em que Adamov explica que "tentou fazer com que a manifestação (do) conteúdo (de suas peças) coincidisse literalmente, concretamente, corporalmente com o próprio conteúdo". Quanto à literalidade das peças de Adamov, no capítulo anterior demos o exemplo esclarecedor do personagem mutilado psiquicamente e fisicamente ${ }^{11}$.

De fato, mais que o exemplo do Mutilado (personagem de La Grande et la petite manoeuvres de Adamov), é a ideia geral da literalidade que Barthes e Dort subscrevem. Os transbordamentos corporais voluntariamente teratológicos de lonesco, Beckett, Adamov deixam bastante em dúvida, ao menos nos primeiros tempos, os dois editores de Théâtre populaire. Em compensação, o princípio da literalidade, cuja única finalidade é afirmar a presença e a materialidade do teatro, os seduz. A literalidade torna-se a via privilegiada para o surgimento da teatralidade. O que fascina Barthes no verdadeiro protagonista de Le Ping Pong - quero dizer, o bilhar elétrico - é o que o autor de Mitologias chama de "objeto literal", um objeto que não tem por função dramatúrgica e cênica simbolizar, mas simplesmente estar presente e, por meio dessa presença que teima, produzir ação e situações (mesmo que sejam ação e situações "de linguagem"). Isso se explica porque a geração que defende essa dramaturgia do Estar-aí sustenta, igualmente, o Nouveau Roman. Dort será um dos primeiros a desenvolver uma temática - em seus artigos "Tempo das coisas" e "Romances brancos" dos Cahiers du Sud ou de Lettres nouvelles, - que anuncia o Nouveau Roman; e sabe-se da relação forte e tempestuosa que Barthes mantém, durante anos, com Robbe-Grillet.

Teatro ou romance, trata-se de exorcizar definitivamente o demônio da analogia. Terminar de uma vez por todas com uma arte fundada no primado da interioridade,

10 Bernard Dort, "Le Corps du theatre", Art Press, n. 184, outubro 1993.

11 Antonin Artaud, Oeuvres completes, t. II, Gallimard, 1961 (Sou eu, JPS, que sublinho) 
da psicologia, da profundidade. "Para nós, a superfície das coisas deixou de ser a máscara de seu coração", declara o autor de Gommes. O que se tornou insuportável para os escritores e homens de teatro foi a manutenção da dicotomia neo-platônica ideia/aparências, alma/corpo - em que o segundo termo é considerado apenas uma má tradução do primeiro. No início dos anos cinquenta, parece ter chegado a hora de um teatro inteiramente dedicado ao presente da representação e ao evento cênico. No entanto, à condição de liquidar, definitivamente, a parcela da herança hegeliana que afirma que na cena, sempre, definitivamente, os conceitos é que são representados, vestidos, animados.

É uma mudança de perspectiva semelhante à promovida pelo Nouveau Roman que os editores da revista Théâtre populaire querem realizar no teatro. No entanto, para Barthes e Dort, o campeão dessa revolução não é um escritor próximo do Nouveau Roman como Beckett, por exemplo, ou os sustentáculos mais radicais da literalidade - Adamov ou o primeiro lonesco; esse campeão é Brecht, na via dos espetáculos do Berliner Ensemble apresentados em Paris a partir de 1954. Em relação à vanguarda dos anos cinquenta, cujas obras os editores da revista Théâtre Populaire julgam atemporais e não-históricas, a dramaturgia brechtiana tem a imensa vantagem de integrar a dimensão da História, do social, do político ao partido da literalidade... À distância, e com todo respeito ao contexto, pode-se perguntar se o modo como Dort e Barthes rejeitam Beckett nesse momento, relegando-o às trevas de um teatro metafísico e de vanguarda burguesa (e o próprio Adamov faz com que suas peças iniciais tenham destino semelhante) não tem algo de excessivo e injusto... A reprovação retrospectiva que se pode fazer aos críticos de Théâtre populaire é a de ter confundido a obra dos dramaturgos dos anos cinquenta com a leitura idealista que deles foi feita (em Beckett, Anouilh privilegia o símbolo da ausência de Godot, em lugar da hiperpresença "literal" de Vladimir e Estragon). No entanto, a questão fundamental está colocada: será que o teatro pode continuar a fazer, como acontece em Sartre, a passagem incessante do sensível para o inteligível e a anulação permanente da forma cênica em proveito de ideias, teses e outras "mensagens"? Não chegou a hora de o teatro destacar esse momento de pura teatralidade, em que o sensível torna-se significante?

No fundo, o princípio da literalidade nada mais é que um gigantesco efeito de distanciamento (brechtiano) ou de inquietante estranheza (freudiana) em que a presença cênica dos objetos e dos seres, usada e banalizada por tantos séculos de representação, recupera repentinamente sua potência arcaica e enigmática. Essa 
exigência de literalidade que os textos de Adamov, Barthes e Dort expressam claramente vem selar o pacto de um teatro "refundado" na teatralidade... A série de artigos de Barthes consagrados à Mãe Coragem e à arte do Berliner Ensemble, bem como a Leitura de Brecht de Dort, estabelecem que no teatro da literalidade e da teatralidade o sentido nunca é global; é sempre local e fragmentário. O sentido é sempre apreendido na materialidade da cena, ela própria espaçada, "como os caracteres de impressão na página de um livro"12, no vazio inaugural do teatro.

Para Barthes, o exemplo brechtiano oferece a oportunidade de revisar a questão do sentido até mesmo para além do teatro: da "isenção" ou da "decepção" com o sentido, ligada à Kafka e ao surgimento do Nouveau Roman, ele passa à "suspensão" do sentido, sob influência direta do teatro épico. Ou seja, passa a levar em conta o destinatário da obra épica, seu papel de leitor ou espectador ativo, ocupado em destrinchar o enigma do sentido depois que a leitura ou a representação terminaram. De fato, Barthes deve à literalidade brechtiana - essa teatralidade polifônica, fundada na "espessura de signos", na "superposição de sentidos" - sua concepção mais afinada da razão semiológica. A pura presença teatral é aquilo que dá a ver um objeto, um corpo, um mundo em sua hipervisibilidade fragmentária, em sua opacidade mesma, que me permite vê-la e decifrá-la sem esperança de chegar ao final de sua decifração.

Assim, o conteúdo do espetáculo não esvazia sua forma; a forma, ao contrário, constitui o elemento resistente que absorve minha atenção e canaliza minha reflexão. $A$ literalidade realiza o estado máximo de concentração do objeto teatral e faz com que eu me concentre nesse objeto. Por meio da intensificação e densidade extremas da matéria teatral - que afeta tanto os atores e a linguagem quanto o cenário e os objetos -, o espectador fica sem escapatória e se vê confrontado com o Estar-aí mútuo dos homens e do mundo. Portanto, a literalidade é também essa (falsa) opacidade, essa cegueira que permite ver no refletor do teatro: "Vemos Mãe Coragem cega", escreve Barthes, "vemos que ela não vê"; fórmula que ecoa um Fragmento de 1964 sobre o diálogo platônico: "Ver o não ver, ouvir o que não se ouve (...). Ouvimos o que Ménon não ouve, mas só ouvimos por causa da surdez de Ménon"13.

No entanto, a reivindicação de literalidade que Dort e Barthes priorizam, nos anos cinquenta e sessenta, hoje pode parecer insuficiente. Para certos detratores,

12 Arthur Adamov, "Avertissement à La Parodie et à L'Invasion", em Ici ET Maitenant, Gallimard, Coll. "Pratique du Théâtre", 1964.

13 Walter Benjamin, Essais sur Bertolt Brecht, Petite collection Maspero, n. 39, 1969. [Walter Benjamin, 
sob a capa de literalidade e teatralidade Brecht só propõe um teatro predicante e militante disfarçado. $\mathrm{E}$, mesmo que se chegue a provar que a única pedagogia proposta pelo teatro épico é de ordem heurística e socrática, pode-se confrontar, ainda, com a objeção de que Brecht não coloca em xeque, suficientemente, o conceito de representação no que implica em se furtar a esse presente absoluto, a esse "mais-que-presente" de pura situação em presença do teatro. Se nos anos oitenta e noventa apareceram novas exigências de literalidade e teatralidade, elas se ligaram a um evento cênico que deveria ser pura presentação, pura presentificação do teatro, a ponto de apagar toda ideia de reprodução, de repetição do real.

Se o Novo romance e o Novo teatro estão razoavelmente distantes de nós (restam as obras em sua singularidade, em particular a de Beckett), Brecht, por seu lado, tornou-se suspeito aos olhos de muitos; portanto, a tentação de reavaliar negativamente o princípio de literalidade dos anos cinquenta é grande, seja ao propor uma versão mais potente da literalidade, seja ao desqualificá-la... Hoje, certos homens de teatro pretendem dar mais espaço e destaque ao Estar-aí do teatro. Também procuram dilatar o instante teatral, ao distanciar o jogo de sua significação, ao liberar a teatralidade, definitivamente, de toda função de comentário em relação à ação (a teatralidade brechtiana continua subordinada ao "comentário do gestus"14).

Mas, no centro dos questionamentos atuais, pode-se pensar também em questionar o abuso da literalidade e essa espécie de medo do sentido que ela engendra. "A profundidade não é mais o que era. Pois enquanto o século XIX assistiu a um longo processo de destruição das aparências em proveito do sentido, o século XX desenvolveu um processo gigantesco de destruição do sentido... em proveito de que? Não desfrutamos mais das aparências nem do sentido"15. Aqueles que fazem teatro hoje e refletem sobre ele não deveriam ficar indiferentes à constatação irônica de Baudrillard.

\section{Da cena ao texto}

Definir a teatralidade como se faz, frequentemente, a partir do distanciamento do teatro em relação ao texto não é falso, mas pode levar ao uso unívoco e abusivo da noção.

\footnotetext{
14 Roland Barthes, "Mère courage aveugle", Théâtre populaire, n. 8, julho-agosto 1954, republicado em Oeuvres completes, tomo 1, Seuil, 1993 [Roland Barthes, "Mãe coragem cega", in; "Fragment", Oeuvres complètes, 1, op. cit.

15 Sobre o comentário de gestus, ver os Écrits sur le théâtre, t. 2, de Brecht, editado pela l'Arche, em particular o "Petit Organon" [Bertolt Brecht, "Pequeno Organon para o Teatro", in. Sobre a necessária subordinação da teatralidade ao comentário do Gestus: Roland Barthes, "Les Maladies du costume de théâtre", Théâtre populaire n. 12, março-abril 1955, republicado em Oeuvres completes, 1, op. cit. [Roland Barthes.
} 
Em todo caso, Barthes preveniu-nos contra tal redução: ao mesmo tempo em que define a teatralidade como "o teatro menos o texto", introduz o paradoxo que faz da teatralidade um "dado de criação, não de realização" ("Em Ésquilo, em Shakespeare, em Brecht, o texto escrito é previamente tomado pela exterioridade dos corpos, dos objetos, das situações", Barthes precisa). A partir daí, pode-se concluir que a posição barthesiana é ambígua? Sim, se considerarmos que não esclarece, de fato, as relações que o texto mantém com os outros componentes da representação teatral. Não, na medida em que preserva a possibilidade de uma relação dialética, ou de uma tensão, entre esses componentes.

Para Barthes, para Dort, a teatralidade é aquilo que permite pensar o teatro não sem o texto mas, de modo recorrente, a partir de sua realização ou seu devir cênico. Vontade de voltar ao hic et nunc da representação e de reinstalar o teatro em sua dimensão propriamente cênica, depois de muitos séculos de subserviência à literatura (Sua Majestade, diz amavelmente Baty, enquanto Artaud denuncia a atitude de "gramáticos e invertidos, em resumo, de ocidentais"). Mas, sobretudo, vontade de libertar o teatro de sua identidade literária, abstrata e atemporal, para recuperar sua abertura para o mundo, para o real. Nesse sentido, a teatralidade reinstitui a arte do teatro enquanto ato.

Os animadores de revista Théâtre populaire certamente não foram os únicos nem os primeiros a expressar essas preocupações. Henri Gouhier, por exemplo, sempre defendeu a ideia de que o teatro deveria ser pensado a partir do núcleo da representação. "A representação," escreve, "está inscrita na essência da obra teatral; só existe realmente no momento e no lugar em que se realiza a metamorfose. Portanto, a representação não é um suplemento de que se poderia, a rigor, prescindir; é um fim nos dois sentidos da palavra: a obra é feita para ser representada; é essa sua finalidade; ao mesmo tempo, a representação define um acabamento, o momento em que, enfim, a obra é plenamente ela mesma"16... E cabe ao filósofo usar a expressão "texto-partitura"

No entanto, no que diz respeito à representação, a posição de Gouhier (ou a de seu contemporâneo Touchard, bastante próxima) continua a fazer parte desse "textocentrismo" denunciado por Dort. Para o muito galilaico autor de Leitura de Brecht, o texto pode ser colocado no centro da representação teatral como nenhum outro componente cênico. Em ensaio claro e sábio, "O texto e a cena: uma nova aliança"17, Dort mostra como nasceu e se desenvolveu a concepção moderna de uma obra dramática

16 Jean Baudrillard, Cool memories, Éditions Galilée, 1987.

17 Bernard Dort, La Représentation émancipée, Actes-Sud, Coll. "Le temps du theatre", Arles, 1988. 
incompleta, aberta, à espera da cena... Quase a despeito de si mesmo, Hegel confirma a existência de uma parte criativa - e não simplesmente interpretativa ou ilustrativa do ator que, por meio da mímica, do jogo mudo, vem preencher as lacunas de um texto em si mesmo inacabado. "O texto e a cena..." faz referência a essas páginas da Estética, em que se nota, a respeito do drama como novo gênero, que "o poeta abandona aos gestos aquilo que os antigos só exprimiam pelas palavras." Tanto quanto a Hegel, Dort poderia remeter à função criativa da "pantomima" em Diderot e Lessing que, com frequência, está em contradição com as palavras.

Mas se Dort denuncia o textocentrismo para afirmar a autonomia da representação, recusa-se, categoricamente, a ceder ao mito "moderno" de uma teatralidade que seria incompatível com a existência do texto. Chega mesmo a acrescentar, ao paradoxo barthesiano da teatralidade, um segundo paradoxo: "O teatro sem texto", afirma, referindo-se especialmente a Artaud, "é um sonho de escritor (que) só pode ser pensando e expresso no texto, por meio da escritura. Daí o silêncio teatral a que são condenados esses profetas". De fato, trata-se de distinguir a ruptura necessária com um teatro puramente literário, um teatro sem corpos, do impasse de uma posição mais extrema que consiste no repúdio ao texto de teatro. Em Dort, a preocupação de encontrar o bom equilíbrio - ou o desequilíbrio dinâmico - vai a tal ponto que ele se esforça por resolver as contradições do autor de O Teatro e seu duplo: "Quando Antonin Artaud citava Woyzeck entre as primeiras obras a serem incluídas no repertório de seu teatro da Crueldade, sem dúvida entrava em contradição com seu desejo de acabar com as obras-primas do passado, mas também pressentia a nova aliança entre o texto e a cena que bem poderia caracterizar o teatro de hoje - para além da pseudoposição entre texto e encenação, entre um teatro do texto e um teatro teatral'.

Ainda que ligado à epifania da representação - a esse momento em que se manifesta a teatralidade - Dort continua atento à problemática do texto teatral, em particular do texto contemporâneo, e leva em conta as resistências desse último à mimesis. Para Dort não parece uma aberração o texto recusar-se a jogar completamente o jogo da representação - pois, como escreveu Duras, "é quando o texto é representado que se está mais distante do autor.' Para dizer a verdade, Dort, ao contrário de Barthes, não é um homem da aporia, mas das passagens. Em "O texto e a cena: uma nova aliança" ou, pouco mais tarde, em A representação emancipada, procura traçar os contornos - para ele bastante "razoáveis" - de uma nova utopia (pós-brechtiana) da representação. Mas, 
ao propor uma "nova aliança", Dort nos previne, sobretudo, contra os dois perigos que ameaçam as relações entre a cena e o texto:

- Por um lado, essa atitude francamente reacionária, mas que ganha cada vez mais espaço, que consiste em querer restaurar o teatro literário, o "teatro de texto". Pois não foi Jacques Julliard (e poderia ser Alain Finkielkraut) que afirmou, há alguns anos, em uma de suas crônicas do Nouvel Observateur, que "enquanto o teatro não retornar ao lugar onde se faz ouvir a palavra sagrada do poeta; enquanto os encenadores atuais, esses tiranos mal educados, não deixarem de ser arrogantes com o autor, o contrato dramático, essa aventura a três que une autor, intérpretes e espectadores em torno de um texto, permanecerá despedaçado, desonrado, destruído"? ... Contentemo-nos de devolver Julliard e seus preconceitos (que, diga-se de passagem, são anteriores ao surgimento da encenação moderna) ao que Dort nos diz sobre "os maiores textos de teatro": "à leitura (eles) parecem problemáticos", "complexos a ponto de parecerem incoerentes", "excessivos no limite da desordem", porque "tomam partido, deliberadamente, de seu próprio inacabamento" e "fazem apelo à cena".

- Por outro lado, uma proposta que não é menos vaga, incerta e arriscada só porque toma partido da "emancipação" da representação (acredito que a expressão remonta a Evreinoff). É assim que Alain Badiou, em suas Dez teses sobre o teatro (Dix thèses sur le théâtre) parece afastar a questão do texto ao reduzi-lo a uma essência eterna que somente a representação pode levar à instantaneidade, à imediaticidade, em uma palavra, à vida. Sem dúvida Dort concordaria com a afirmação de Badiou de que "a ideia-teatro no texto e no poema está incompleta, e que a encenação não é interpretação, mas complementação". Mas imagino que acharia menos convincente apresentar o teatro como um "agenciamento de componentes materiais e ideais extremamente disparatados, cuja única existência é a representação". Em suas teses, Badiou simplesmente esquece que na representação o texto tem, forçosamente, estatuto e função diferentes dos outros componentes... Sobretudo por falta: o texto é o único elemento que existe de modo autônomo - enquanto texto escrito - no evento da representação; transforma-se, metamorfoseia-se, pode até mesmo ser abolido durante sua manifestação... Em seguida, por excesso: sua forma de invasão é diferente de qualquer outro elemento presente em cena - através dos corpos, das vozes, do espaço, e até mesmo do espírito dos espectadores, que podem conhecê-lo antes da representação. 


\section{De uma polifonia que virá}

Será que é preciso passar da proposição adamoviana, que Dort e Barthes subscreveram - "em minha concepção, o teatro está completa e absolutamente ligado à representação" - para a de Badiou, que pretende que a teatralidade só exista "na e para a representação". O inconveniente da "ideia-teatro" segundo Badiou é que ao remeter à articulação - ou como diria Dort, ao "jogo" - entre os diferentes componentes cênicos, só agrava a ambiguidade já notada em Barthes. De certo modo, a "ideia-teatro" vem preencher o espaço vazio deixado pelo gestus brechtiano, pedra angular da concepção de teatro crítico elaborada por Dort e Barthes: "Toda obra dramática pode e deve reduzir-se ao que Brecht denomina gestus social, a expressão exterior, material, dos conflitos da sociedade de que é testemunha. Evidentemente, cabe ao encenador descobrir e manifestar esse gestus, esse esquema histórico particular que fundamenta todo espetáculo: para isso, tem à sua disposição o conjunto das técnicas teatrais: o jogo dos atores, a espacialização, o movimento, o cenário, a iluminação (...), o figurino". A vantagem do gestus - hoje considerado obsoleto, como todo teatro "da fábula" - sobre a "ideia-teatro" é ser, ao mesmo tempo, transcendente em relação ao conjunto dos componentes da representação e estar indexado no texto. O gestus existe como globalidade, como ponto de vista geral sobre o texto, mas também como unidade (no sentido semiológico) a partir da qual o texto pode ser lido, decupado, comentado...

Fazendo o luto do brechtianismo, e a fim de preservar um certo "jogo" ou um certo "uso" do teatro e do mundo real, Dort esforçou-se por elaborar essa utopia de ligação, mais técnica que política, que eu evocava acima. Foi assim que escolheu ir além da metáfora brechtiana da revolução copernicana do teatro e anunciar uma revolução propriamente einsteiniana... Para tornar palpável essa esperança, evoca um modelo de representação ideal: "A revolução copernicana do princípio do século tornou-se uma revolução einsteiniana. A inversão do primado de texto e cena transformou-se em relativização generalizada dos elementos da representação teatral, uns em relação aos outros. Renuncia-se à ideia de uma unidade orgânica, fixada a priori, e até mesmo de uma essência do fato teatral (a misteriosa teatralidade) para conceber o teatro como uma espécie de polifonia significante, aberta sobre o espectador"18.

18 Alain Badiou, "Dix thèses sur le theatre", op. cit. 
A "representação emancipada", no sentido dortiano, certamente tem muito a ver com a "polifonia" barthesiana; entretanto, é marcada pela recusa de uma teatralidade "ecumênica". Dort preconiza um tipo de relação violentamente contraditória entre os diferentes componentes da representação que Brecht previa na origem de sua teoria das "artes-irmãs" ("Schwesterkünste"), mas que teria esquecido parcialmente: "Por conta de seu privilégio e de suas obrigações de autor e encenador, e também de editor do Berliner Ensemble, sem dúvida sacrificou a independência dessas artes-irmãs a uma concepção dramatúrgica unitária das obras que apresentava. Mas sua lição vai além de sua prática. Desenha a imagem de uma representação não unificada, cujos diversos elementos entrariam em colaboração, até mesmo em rivalidade, em lugar de apagar suas diferenças e contribuir para a edificação de um sentido comum"19.

Para Dort, "jogo" é sempre sinônimo de luta e combate. Mas, ao mesmo tempo, esse voluntarismo do Dort-teórico é atenuado e corrigido pelo hedonismo que é a marca do Dort-espectador. Ora, para esse espectador de dimensão romanesca "o prazer do teatro" sempre adquire uma cor nostálgica, quase melancólica. Será que isso acontece porque sua atividade de crítico permanece fundada, para sempre, nos combates travados com Barthes no tempo de Théâtre populaire? Ou porque nenhum espetáculo, desde Mãe Coragem na encenação de Brecht ou A vida de Galileu dirigida por Strehler, pode responder totalmente à expectativa criada por esses? Ou ainda, será que se trata de um sentimento mais geral e misterioso, diretamente ligado ao surgimento da teatralidade: o sentimento da perda do teatro para o próprio teatro? Para Bernard Dort, a representação teatral sempre aparece como o lugar da falta por excelência, a experiência de privação de um espaço e um tempo para sempre inalcançáveis. Como se hoje a paixão do espectador só pudesse expressar-se por um permanente desencanto. Desilusão que o artista (ele próprio um espectador desiludido do esforço de fazer teatro) partilharia com o público. Em eco contraditório ao "Eu não vou mais ao teatro" de Barthes, Dort não cessa de nos advertir, mezzo vocce, que o teatro jamais para de nos abandonar, de desertar de si e de nós. Em todo caso, foi sob o signo da intensa nostalgia que Dort viu e viveu Sur la grande-route de Grüber: "Um momento de repouso no movimento infinito de Grüber de abandono do palco" (...) Sur la grande-route fala da última felicidade possível."20.

19 Roland Barthes, Les Maladies du costume de théâtre", op. cit. 
Persistir na tarefa (beckettiana) de acabar (mais uma vez) com o teatro, e sempre sonhar com o retorno ao início: talvez seja esse o último paradoxo da teatralidade. Pois o teatro só se realiza verdadeiramente fora de si, quando consegue libertar-se de si... Ao produzir no teatro, a cada vez, o vazio do teatro.

\section{Referências Bibliográficas}

ADORNO, Theodor W. Teoria estética. Lisboa: Ed. 70, 2011.

BARTHES, Roland. O império dos signos. Trad. Leyla Perrone-Moisés. São Paulo: Martins Fontes, 2007.

BAUDRILLARD, Jean. Cool memories. São Paulo: Estação Liberdade, 1996.

BENJAMIN, Walter. O que é o teatro épico, IN Flávio R. Kothe e Florestan Fernandes (org.). Walter Benjamin. Sociologia. São Paulo: Ática, 1991, p. 202-218.

DORT, Bernard. A Representação Emancipada. Revista Sala Preta, Vol. 13.1. São Paulo: USP/PPGAC, 2013. 